\title{
Modelos de tomada de decisão e sua relação com a informação orgânica
}

Mariana Lousada

\begin{abstract}
Mestranda do Programa de Pós-Graduação em Ciência da Informação. Universidade Estadual Paulista (Unesp)
\end{abstract}

Marta Lígia Pomim Valentim

Profa. Dra. do Programa de Pós-Graduação em Ciência da Informação. Universidade Estadual Paulista (Unesp)

O processo decisório compreende a aplicação de diferentes modelos de tomada de decisão, cada um deles pertinente a uma determinada situação. Entre eles, destacamos como principais os modelos racional, processual, anárquico e político. Para este trabalho, utilizamos os conceitos de Choo (2003), por se tratar de uma das principais obras a respeito do tema existente na literatura e, assim, analisamos cada um dos modelos propostos pelo autor. A partir da análise dos modelos, foi possível estabelecer relações entre eles e maneira pela qual a informação orgânica - produzida internamente à organização, participa do processo decisório, mais especificamente no âmbito de cada modelo. Por último, a partir das inferências realizadas, propomos um novo modelo de tomada de decisão, cuja base de sustentação é a informação orgânica.

Palavras-Chave: Modelos de tomada de decisão; Processo decisório; Informação orgânica; Informação arquivística; Modelo orgânico de tomada de decisão.

\section{Decision making models and their relationship with organic information}

The decision making process encompasses the application of different decision making models, each of them concerning a specific situation. Among them, one can cite the political, anarchic, procedural, and rational models as the most important ones. For this paper we utilize the concepts of Choo (2003), since they are the most 
important works in the literature about the subject. We, thus, analyze each model proposed by the author. From the analysis of the models it was possible to establish relationships between the models and the way through which organic information - produced internally to the organization -, participates in the decision making process, more specifically in the scope of each model. Finally, from the inferences carried out, we propose a new decision making model, which supporting basis is organic information.

Keywords: Decision making models; Decision making process; Organic information; Archivist information; Decision making organic model.

Recebido em 15.02.2010 Aceito em 10.01.2011

\section{Introdução}

O estudo sobre o processo decisório organizacional tem sido objeto de investigação de diversos teóricos e gestores, pelo menos nos últimos 50 anos. A importância das reflexões sobre essa temática é indiscutível para a sociedade contemporânea, uma vez que as organizações necessitam, cada vez mais, de decisões acertadas, em um espaço de tempo mais reduzido.

O uso de modelos de tomada de decisão permite aos gestores compreender a estrutura organizacional e as relações complexas inerentes aos processos desenvolvidos nesse âmbito. Portanto, há a crescente relevância no que tange à investigar e construir modelos, que proporcionem uma melhor aplicabilidade de métodos e técnicas no processo de tomada de decisão organizacional, cuja base é a informação, visto que se constitui em recurso fundamental para o referido processo.

A organização que não tem informação para subsidiar suas decisões estratégicas, bem como a sua gestão, estará em desvantagem em relação às outras organizações do mesmo segmento, porquanto não será possível analisar, em um tempo mínimo, as alternativas de decisão, além de reproduzir eficazmente o resultado decorrente da decisão tomada.

Beuren (2000, p. 18) enuncia as vantagens dos modelos aplicados ao processo decisório: simplifica a visualização geral das variáveis sem alterar a essência; simplifica a visualização da amplitude das variáveis sem alterar a essência; auxilia na identificação de possíveis relações entre os elementos; permite compreender relações complexas; serve como base para estabelecer e aprimorar parâmetros.

Ressalta-se que a utilização de modelos pode levar à limitação na identificação das variáveis determinantes de uma situação, conforme explica Beuren (2000, p. 20): "[...] o modelo de decisão adotado pelo gestor irá depender do conjunto de variáveis envolvidas, do grau de 
controle sobre as variáveis, do nível de certeza associado à decisão, dos objetivos do decisor, entre outros". Nesse sentido, este trabalho centrouse nos quatro modelos apresentados por Choo (2003), buscando verificar sua relação com a informação orgânica.

\section{Modelos de tomada de dfcisão}

O processo decisório compreende a aplicação de diferentes modelos de tomada de decisão, cada um deles pertinente a uma determinada situação. Entre eles, destacamos como principais os modelos racional, processual, anárquico e político. Utilizamos como referencial teórico os conceitos de Choo (2003), por se tratar de uma das principais obras a respeito do tema e, dessa forma, analisamos cada um dos modelos propostos pelo autor.

\subsection{Modelo racional}

O modelo de tomada de decisão racional é o mais sistematizado e estruturado entre todos, pois pressupõe regras e procedimentos prédefinidos, que devem ser seguidos para que se possa atingir um bom resultado. Neste tipo de modelo, predomina em sistemas fechados, cuja estrutura organizacional é altamente burocrática e as diretrizes da organização são definidas através de regras formais. Trata-se de um ato orientado para se atingir os objetivos, por meio da solução de problemas, ou seja, é um comportamento regulado por normas e rotinas, de modo que a organização possa agir de uma maneira procedimental e intencionalmente racional. March (1994) explica que este modelo foi inicialmente desenvolvido por March e Simon (1975), ajustado por Cyert e March (1992) e novamente ajustado por March (1994).

As questões-chave do modelo racional são: qual é o problema?; quais são as alternativas?; quais são os custos e vantagens de cada alternativa?; e o que deve ser observado como padrão para tomar decisões em situações similares?

Stoner e Freeman (1992, p.187-188) explicam que o processo decisório não se finaliza com a escolha da decisão, isto é, após a escolha da melhor alternativa há o monitoramento da decisão, que se refere à análise e acompanhamento dos resultados obtidos, tanto os positivos quanto os negativos, da escolha implantada.

Segundo Robbins (2005, p.114):

[...] quando enfrentam problemas simples, com poucas alternativas de ação ou quando o custo de procurar e avaliar alternativas são pequenos, o modelo racional oferece uma descrição bastante precisa do processo decisório.

Este modelo presume uma metodologia que pode ser aplicada em distintas situações, por se tratar de um método sistematizado, define bem 
as etapas a serem seguidas pelo decisor, cujo objetivo é obter um resultado satisfatório e, portanto, é de fácil aplicação e entendimento.

Existem muitos aspectos que influenciam diretamente a tomada de decisão racional, embora alguns aspectos não sejam racionais. Por essa razão, não se pode afirmar que o processo de tomada de decisão seja puramente racional. Teodósio, Silva e Rodrigues (2007, p. 2) afirmam que o processo decisório racional está estruturado da seguinte forma:

a) Detecção do problema: através dos sensores que a organização possui e que possibilitam aos gestores tomar conhecimento das disfunções organizacionais, que as levam para caminhos diferentes dos planejados, comprometendo a consecução de suas metas;

b) Início do fluxo do processo decisório:

- Coleta de informações: fase de diagnóstico, reunião da maior quantidade de dados possíveis;

- Análise criteriosa de informações: estabelecimento de uma correlação das informações coletadas com variáveis presentes no ambiente, atribuindo-Ihes relevância, para serem utilizadas na solução de problemas;

- Identificação de alternativas: busca de alternativas para eleger um critério de julgamento das alternativas propostas, através de uma lista de quesitos com pesos de importância para a organização;

- Opção pela melhor alternativa: segundo um mecanismo prédefinido, para assegurar a legitimidade da escolha; e

- Consecução dos objetivos organizacionais: através da implantação da alternativa compreendida como a melhor, espera-se que isso redunde na consecução dos objetivos organizacionais no tempo previsto.

No processo decisório, para se fazer uma escolha totalmente racional, o indivíduo teria que identificar todas as alternativas existentes, prever as consequências de cada alternativa e avaliá-las de acordo com os objetivos e preferências (CHOO, 2003, p. 265).

Observamos que há consenso na literatura analisada quanto ao entendimento de que tomar uma decisão totalmente racional é uma tarefa praticamente impossível, pois o tomador de decisão não tem condições de possuir conhecimento sobre todas as variáveis influenciadoras do processo; isso porque, no momento da coleta de informações, já se pressupõe a análise inicial das alternativas e, também, das prováveis consequências que cada uma pode causar.

Nesse contexto, Robbins (2005, p. 114) define 'racionalidade limitada' como a "construção de exemplos simplificados que atraem os aspectos essenciais dos problemas, sem capturar toda a sua complexidade"; isso porque o indivíduo não tem condições cognitivas para se apropriar de todas as informações que lhe são oferecidas e, nessa circunstância, somente o que julga importante é assimilado. Trata-se de 
minimizar o problema, dar enfoque e supervalorizar os aspectos mais relevantes ou mais visíveis.

A limitação da racionalidade descreve o processo de tomada de decisões utilizado na contratação da maioria dos novos funcionários. Após identificar a necessidade de um novo funcionário, os executivos tentam ajustar as exigências do cargo à qualificação dos candidatos. Depois, eles entrevistam um número limitado de candidatos e escolhem aquele que acreditam ser o que oferecerá um nível aceitável de desempenho [...] O processo de tomada de decisões racionais pressupõe que levantemos informações objetivamente. Mas isso não acontece. Nós levantamos as informações seletivamente. O viés de confirmação representa um tipo específico de percepção seletiva. Buscamos informações que corroborem nossas escolhas anteriores e desprezamos aquelas que as contestam (ROBBINS, 2005, p. 116).

Essa situação ocorre porque o indivíduo despreza informações que contrariam a decisão tomada, ou seja, o indivíduo tende a ignorá-la ao invés de analisá-la; por outro lado, as informações que confirmam a decisão são supervalorizadas. No processo de tomada de decisão, a maneira mais fácil para se obter um resultado satisfatório refere-se a analisar as informações que contradizem a decisão escolhida, pois, através dessa análise, é possível detectar seus pontos fracos, isto é, qual é a possibilidade da decisão falhar ou de não se obter o resultado esperado. Já as informações que corroboram a decisão são comprometidas, principalmente, pelo indivíduo que tende a sentir-se confiante com a decisão tomada.

\subsection{Modelo processual}

O modelo processual elucida as fases e os ciclos que subsidiam as atividades decisórias, aparentemente complexas e dinâmicas. Foi desenvolvido, inicialmente, por Mintzberg, Raisinghani e Théorêt (1976).

As questões-chave deste modelo são: quais são as organizações que atuam nesse tipo de circunstância?; quais são as rotinas e procedimentos utilizados usualmente?; quais são as informações disponíveis?; e quais são os procedimentos padrões utilizados nesses casos?

Este modelo concentra-se nas fases, nas atividades e na dinâmica dos comportamentos decisórios (CHOO, 2003, p. 283). O modelo tem um grande número de elementos: três fases decisórias principais, três rotinas de apoio às decisões e seis grupos de fatores dinâmicos.

As três principais fases decisórias são: 
a) Identificação: reconhece a necessidade de tomar uma decisão e desenvolve a compreensão das questões implicadas na decisão. Consiste em rotinas de reconhecimento e rotinas de diagnóstico do problema;

b) Desenvolvimento: desenvolvimento de uma ou mais soluções para um problema, crise ou oportunidade. Consiste na busca (memória, passiva, armadilha, ativa) e rotinas de criação;

d) Seleção: avalia as alternativas e escolhe uma delas ( $\mathrm{CHOO}$, 2003, p. 283-287).

As três rotinas de apoio no modelo processual são:

a) Rotinas de controle: guiam o processo decisório e consistem em planejamento, determinam os limites do espaço da decisão;

b) Rotinas de comunicação: reúnem e distribuem a informação como parte do processo decisório;

c) Rotinas políticas: importantes nos processos estratégicos, pois podem assumir a forma de barganha, de persuasão ou de cooptação (CHOO, 2003, p. 283-287).

Os seis grupos de fatores dinâmicos são:

a) Interrupções: intervenções ambientais, tanto internas quanto externas;

b) Adiantamento de prazos: diminuir o ritmo das atividades do processo decisório;

c) Feed-back: surge quando os responsáveis guardam os resultados de ações praticadas para serem usadas mais tarde;

d) Ciclos de compreensão: necessários para lidar com questões complexas;

e) Ciclos de fracasso: ocorrem quando não se consegue chegar a uma decisão (CHOO, 2003, p. 283-287).

No modo processual, quando os objetivos são claros, mas os métodos e as técnicas para atingí-los são incertos, a necessidade de tomar uma decisão dá início a um processo marcado por muitas interrupções e repetições. Apesar disso, o processo revela uma linha geral de desenvolvimento, cujo início se dá com o reconhecimento e o diagnóstico do problema, prossegue com a análise das alternativas, por meio de buscas de soluções prontas ou da criação de soluções customizadas, e termina com a avaliação e seleção de uma alternativa que deve ser autorizada ou aprovada (CHOO, 2003, p. 367-368).

Este modelo apresenta várias semelhanças ao modelo racional e suas principais características são confluentes em muitos aspectos. 
Porém, um fator que o difere é a condição de flexibilidade, permitindo que os gestores realizem ajustes quando necessário.

\subsection{Modelo anárquico}

No modelo anárquico, tanto os objetivos quanto os procedimentos são ambíguos. Não há clareza em relação aos problemas e às decisões; é também conhecido como modelo "lata de lixo". Foi primeiramente desenvolvido por Cohen, March e Olsen (1972).

Neste modelo, as organizações não apresentam coerência em relação às situações vivenciadas, visto que os problemas e as soluções são jogados pelos decisores e "as decisões resultam do encontro de correntes independentes de problemas, soluções, participantes e situações de escolha".

Choo (2003, p. 295) explica que:

[...] o modelo anárquico de decisão pode ser comparado a uma lata de lixo, onde vários tipos de problemas e soluções são atirados pelos indivíduos, à medida que são gerados. A decisão ocorre quando problemas e soluções coincidem.

Observamos que se trata de um modelo que não segue nenhum tipo de estrutura e/ou sequência, uma vez que é regido pelo acaso e pela sorte. No modelo anárquico, as decisões são tomadas de três maneiras:

a) Resolução: é a tomada de decisão que ocorre depois de se pensar sobre o problema, por determinado tempo;

b)Inadvertência: uma escolha é adotada rápida e incidentalmente, para outras escolhas serem feitas;

c) Fuga: ocorre quando os problemas abandonam a escolha, quando não há resolução do problema (CHOO, 2003, p.297).

As preferências usadas na tomada de decisão são mal definidas e incoerentes, não são sistematizadas como no modelo racional e processual. A organização trata as situações de forma obscura, assim como os processos e procedimentos não são muito bem definidos, o que gera falta de entendimento e insegurança em seus colaboradores.

\subsection{Modelo político}

O modelo político, conforme o nome já diz, tem na política o mecanismo de apoio à decisão, ou seja, os atores ocupam diferentes posições e exercem diferentes graus de influência, de modo que as 
decisões não resultam em uma escolha racional, mas, ao contrário, resultam da influência dos atores. Este modelo foi inicialmente desenvolvido por Allison (1971), que afirma que a decisão está intimamente relacionada ao poder que cada indivíduo possui e como essa rede de relacionamento se desenha no âmbito organizacional.

As questões chave para este modelo são: quais são os canais usados para produzir ações que resolvam um tipo de problema?; quem são os atores e quais suas posições?; e quais são as pressões que estão influenciando?

Para a abordagem política, a organização é vista como um conjunto de atores, que podem ser indivíduos ou grupos, dotados de interesses e objetivos próprios, controlando diferentes recursos como: autoridade, status, recursos, ideias e informações. A organização não tem objetivos claros a priori. Os indivíduos ou grupos conduzem estratégias particulares a partir de uma situação própria (NIOCHE et al., 1993, p. 307, tradução nossa).

Este modelo é foco de disputas internas de poder e de influência. Muitas vezes, os objetivos pessoais ultrapassam os organizacionais e, às vezes, prejudicam a própria organização. Observamos que esse tipo de disputa é mais acentuado em organizações públicas, porquanto são ambientes altamente influenciados pela política que rege 0 desenvolvimento das estratégias de ação e o desempenho organizacional.

A análise técnica está presente em todos os sistemas políticos. Ela compreende a reunião de fatos, discussão racional de temas, etc.. "[...] 0 processo político de tomada de decisão acaba se assemelhando ao processo racional tradicional, cheio das limitações" (TEODÓSIO; SILVA; RODRIGUES, 2007, p.13), ou seja, todos os modelos de tomada de decisão dependem de informações para definirem e embasarem suas escolhas. Choo (2003, p.300) argumenta que "o modelo político foca nos efeitos dos objetivos conflitantes sobre as decisões". No entanto, a incerteza é mais baixa, pois cada participante do processo tem clareza quanto às alternativas preferidas e os objetivos que pretende atingir.

As decisões e as ações decorrentes se constituem no resultado da troca ou da barganha entre os envolvidos, cujo processo é possível, porque os envolvidos ocupam posições que lhes atribuem algum tipo de poder. "No modelo político há duas categorias de informações buscadas pelos que tomam as decisões: a informação usada para tomar decisões e a informação usada para apoiar decisões já tomadas" (MELTSNER, 1976 apud CHOO, 2003, p. 293), pois é necessário justificar as decisões que foram tomadas, seja antes ou depois da decisão.

Os objetivos organizacionais são superados pelos objetivos pessoais, pois o que se sobressai são as preferências individuais de quem tem o 
poder de decisão. Trata-se de uma constante negociação entre os distintos poderes existentes. 


\section{Informação orgânica}

Informação é insumo do processo decisório empresarial, por isso tem papel fundamental para qualquer modelo de gestão empresarial. Para tomar a decisão certa é preciso que o gestor possua informações internas e externas selecionadas, tratadas, organizadas e acessíveis, de forma que propicie a redução das incertezas. Portanto, é de suma importância que o acesso à informação seja no tempo certo, que a informação seja confiável, bem como seja consistente.

Nomeamos a informação produzida internamente a uma determinada organização como informação orgânica, visto que é gerada em decorrência do cumprimento das funções organizacionais, pelos próprios colaboradores da organização que, ao mesmo tempo, são produtores e consumidores. Por essa razão, a organização deve ter clareza quanto ao valor da informação orgânica, visto que ela se constitui em um recurso importante para os processos organizacionais, inclusive o decisório.

Louzada e Valentim (2008, p. 254) defendem que "a informação orgânica é produzida internamente, sendo produto resultante da execução das funções e das atividades organizacionais", ou seja, é produto do exercício das funções administrativas e se constitui no registro físico das transações de uma determinada atividade, tarefa ou tomada de decisão. Portanto, é insumo para os gestores desempenharem suas funções e tomarem suas decisões.

Lopes (1996, p. 32) explica: "[...] é orgânica a informação que pertence à pessoa ou organização que a acumulou [...]", isto é, a informação orgânica é intrínseca à organização que a gerou. Além disso, a combinação desse tipo de informação pode gerar novas informações de caráter orgânico.

Destacamos alguns tipos de informação orgânica em ambientes organizacionais: diretivas, relatórios, planejamentos, programas, normas, procedimentos, orçamentos, balanços financeiros, atas, contratos, processos de clientes, processos de contratação de pessoal, entre outros (ROSSEAU; COUTURE, 1998, p. 65). Assim, identificar os tipos de informações produzidas internamente permite aos gestores de uma organização detectar possíveis desvios e/ou gargalos de fluxos informacionais, que possam vir a prejudicar a dinâmica organizacional que engloba o processo decisório.

A informação orgânica é um dos elementos que subsidia o processo decisório. É um recurso informacional acessível somente pela própria organização, fato que a torna um recurso informacional estratégico, principalmente após análises diferenciadas em que é possível agregar valor à informação original, transformando-a em um insumo informacional diferenciado.

Este tipo de informação se constitui em um dos fatores responsáveis pela sobrevivência das organizações, visto que desempenha papel relevante no processo decisório, propiciando ao gestor conhecimento sobre os pontos fortes e fracos da organização e, consequentemente, 
proporciona mais segurança no momento da decisão em relação aos riscos e incertezas, influenciando diretamente o desempenho da organização.

A informação orgânica está presente em todos os níveis organizacionais, estratégico, tático e operacional, sendo gerada em todos os setores e por todas as pessoas que nela atuam.

\section{Modelos de tomada de decisão e a informação orgânica}

No modelo racional todas as fases exigem informações. O decisor necessita ter em mãos informações que tenham relação com o objetivo que se pretende alcançar. As informações são obtidas internamente em diferentes setores da organização, ou seja, no modelo racional todos os tipos de informações orgânicas produzidas podem servir para a tomada de decisão.

No modelo processual a busca da informação é mais intensa do que no modelo racional, "em parte porque a coleta de informações expande-se com o tempo e repete-se em muitos ciclos, e em parte porque uma parcela substancial da busca precisa ser feita durante a fase de desenvolvimento do processo" (CHOO, 2003, p. 302). Isso se deve ao fato de que este modelo é mais maleável e pode ser ajustado quando a decisão não for mais satisfatória. Nesse caso, há novamente a busca por novas informações, que possibilitem a formulação de novas alternativas. O uso da informação é centralizado, à medida que repetidos ciclos de processamento da informação tendem para uma solução específica de um problema específico, e que tem de ser submetida à autorização de superiores. Neste modelo, sem dúvida, há maior utilização da informação orgânica, pois se trata de um modelo que privilegia o uso da informação gerada internamente à organização e relacionada aos distintos fazeres organizacionais.

No modelo anárquico a busca intencional de informação ocorre em um nível mais baixo, porquanto as soluções e as alternativas estão desligadas dos problemas, e a informação perpassa as situações decisórias de uma maneira um tanto aleatória. "Não há controle do uso da informação, as soluções ligam-se a problemas por acaso ou por interesse individual, e as decisões são tomadas mais por fuga ou inadvertência do que por resolução racional" (CHOO, 2003, p. 300-301). Neste modelo, são usados todos os tipos de informação orgânica. Contudo, o tomador de decisão não se dá conta de que utiliza a informação para embasar suas decisões. Isso se deve ao fato de ser um modelo que não apresenta estrutura definida ou processos articulados e sistematizados. Por isso, 0 uso da informação apresenta níveis mais baixos do que os demais modelos, ou seja, não há uma busca sistematizada por informações, visando à resolução de problemas, ao contrário, a busca ocorre de maneira inconsciente.

No modelo político, embora a busca de informação possa ser seletiva e orientada para informações que confirmem as opções preferidas, a coleta de informação intensifica-se por duas possíveis razões: as informações que confirmam uma alternativa preferida 
acumulam-se devido a uma ampla sondagem de várias fontes, inclusive as especializadas e as relevantes; e as informações são checadas e verificadas em detalhes, para que sua confiabilidade aumente e elas possam resistir aos argumentos contraditórios. "O uso da informação é fortemente controlado e dirigido, a informação é processada seletivamente, de modo que informações que contrariem pressupostos ou expectativas são ignoradas ou reinterpretadas" (CHOO, 2003, p. 301302).

Observamos que as informações mais utilizadas são de cunho estratégico, oriundas da alta administração e dizem respeito às ações estratégicas da organização. Neste tipo de modelo, as informações são fortemente controladas, pois são estratégicas, para definir metas de médio e longo prazo e, portanto, apresentam elevada utilização no processo decisório, porque os gestores tendem a buscar informações que confirmem suas decisões e não que as contrariem. Há, também, uma preocupação em satisfazer todas as partes envolvidas no processo decisório.

Seja qual for o modelo de tomada de decisão adotado pelos gestores, todos os modelos dependem de informações. No entanto, a busca e o uso da informação variam de acordo com o modelo. Evidenciamos que a informação orgânica é inerente ao processo de tomada de decisão e observamos certo consenso na literatura analisada sobre o entendimento de que os gestores que tomam decisões rápidas estão, provavelmente, utilizando informações de algum tipo. Ressaltamos que mesmo que um modelo não admita usar este recurso, como no caso do modelo anárquico, há a utilização de informação de maneira inconsciente pelos decisores.

Desse modo, observamos que todos os modelos apresentam algum tipo de similaridade, pois todos utilizam a informação como recurso para conhecer pontos fortes e fracos, diminuir as incertezas e os riscos e reconhecer oportunidades no momento da decisão. Contudo, após a análise dos modelos, notamos que nenhum modelo apresenta a informação orgânica como recurso principal do processo decisório.

\section{Modelo orgânico de tomada de decisão}

O modelo proposto se denomina 'Modelo Orgânico', fundamentado no modelo de sistema integrado de gestão da informação orgânica (SIGIO), proposto por Rosseau e Couture (1998, p. 67). O modelo pode ser divido em três fases conforme apresentado a seguir.

A primeira fase visa, principalmente, o reconhecimento das informações que são geradas na organização, quando do cumprimento das funções que lhe competem. Tem por função mapear e monitorar os fluxos informacionais e documentais, identificando em cada setor quem são os produtores de informação e quais podem vir a se tornar potenciais produtores. Ressaltamos que essa tarefa precisa ser realizada em todos os setores da organização, isto porque compreendemos que todas as pessoas são produtores de informação orgânica. 
O mapeamento pode ser executado através da aplicação de questionários, entrevistas estruturadas ou não-estruturadas, a fim de identificar os possíveis produtores. Esse trabalho precisa ser realizado periodicamente, uma vez que surgem novos produtores de informação no ambiente organizacional. Essa etapa é importante, pois alicerça todo o restante do modelo, e se não for bem realizada poderá comprometer todo o processo, porquanto ocorrerão perdas informacionais.

Não são todas as informações orgânicas que podem ser usadas no processo decisório, portanto, é preciso reconhecer quais possuem real potencial. Primeiramente, para não se perder tempo com ações informacionais que não serão aproveitadas; em segundo plano, para que uma informação relevante seja de fato selecionada.

Ressaltamos a importância de não se confundir as informações que foram produzidas, internamente, das que foram produzidas externamente, pois isso comprometeria a principal característica do modelo, o caráter orgânico.

A segunda fase apresenta como características principais a disseminação, acesso e uso das informações produzidas internamente e que foram identificadas como sendo de caráter estratégico. Esta etapa é fundamental para o processo decisório e deve ser executada com muita atenção, pois as informações têm que estar disponíveis no momento adequado para os responsáveis pelas decisões, ou seja, o acesso deve ser rápido para um uso eficiente.

A disseminação e acesso devem ser realizados através de um banco ou base de dados, cuja atualização deve ser constante e, assim, o uso das tecnologias de informação e comunicação (TICs) são essenciais para este tipo de modelo.

As informações devem ser classificadas de acordo com 0 departamento que a gerou, o responsável, o tipo documental, data da inserção, conteúdo/assunto, os níveis de acesso entre os usuários e, também, os níveis de sigilo e de confidencialidade.

Os usuários do sistema devem ser classificados de acordo com as competências organizacionais e o acesso deverá ser relativo às funções e responsabilidades exercidas. Somente a alta administração terá acesso a todos os níveis informacionais. Para tanto, é preciso levar em consideração os seguintes aspectos: quem ou qual setor será responsável pela identificação e seleção das informações?; e quem ou qual setor definirá os níveis de acesso?. As respostas para essas questões devem ser minuciosamente estudadas para a elaboração do sistema, ouvindo, inclusive, os próprios usuários do sistema.

O desenvolvimento do sistema deve ser feito pelo setor de tecnologia de informação, em parceria com o responsável de cada departamento e, também, pelo arquivista. A participação do arquivista, nesse momento, é indispensável, pois é o profissional que possui competências e habilidades para realizar o mapeamento, identificando e selecionando as informações, bem como poderá ser o "gerenciador do sistema", disponibilizando as informações da melhor maneira para os tomadores de decisão. 
O exemplo de uma tela de um banco ou base de dados (FIG. 1) apresenta alguns campos como: identificação do setor/departamento, responsável pela informação gerada/produzida, tipo documental, data em que foi gerada, conteúdo/assunto principal e conteúdos/assuntos secundários, grau de sigilosidade, etc. Certamente outros campos podem ser acrescentados em acordo com as necessidades de cada organização.

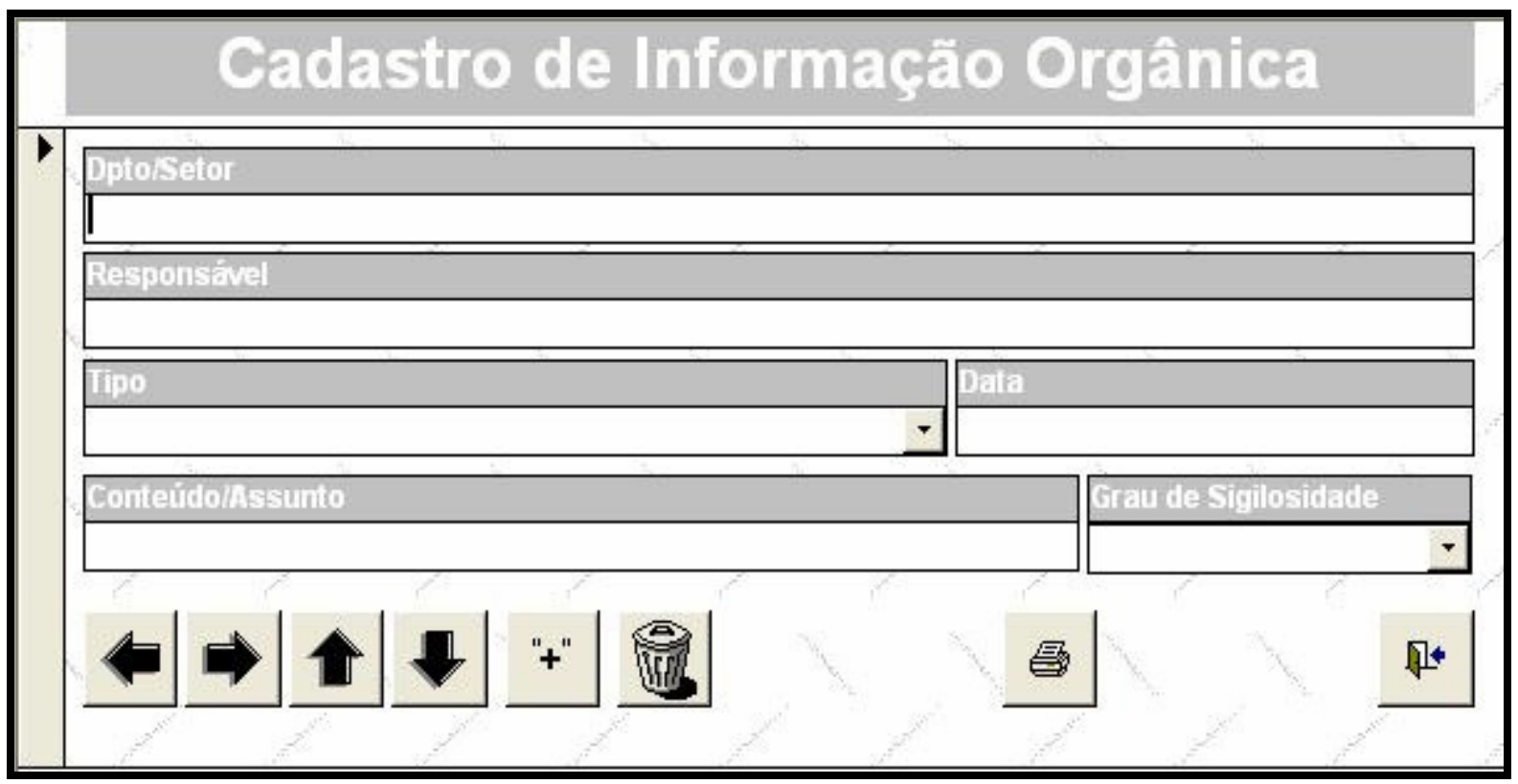

FIGURA 1 - Banco/base de dados de informação orgânica Fonte: Elaborado pelas autoras.

O campo referente ao Setor/Departamento diz respeito à origem da informação/documento, ou seja, onde ela foi gerada/produzida. Trata-se de um campo muito importante, pois vincula a proveniência de ambos. 0 Responsável é a pessoa que gerou/produziu a informação/documento.

O Tipo refere-se à tipologia documental como, por exemplo, relatórios, ofícios etc.; este é um campo relevante, pois pode ser uma das formas de recuperação da informação.

O campo Data indica quando a informação foi gerada/produzida.

o Conteúdo/Assunto é, sem dúvida, o mais importante para o tomador de decisão, visto que é o campo em que consta a descrição da informação/documento, cujo conteúdo propiciará a recuperação da informação/documento, quando o tomador de decisão realizar a pesquisa/busca no sistema.

O grau de sigilosidade pode ser dividido em alto, médio, baixo. Este campo delimita o nível acesso à informação pelos colaboradores que atuam na organização, uma vez que não são todas as informações/documentos que podem ser disponibilizados integralmente.

O banco ou base de dados deve permitir que a pesquisa/busca, bem como a recuperação da informação/documento, seja realizada através de qualquer campo existente no sistema. 
O melhor ambiente para armazenar esse tipo de sistema é a Intranet da organização, isso porque são informações/documentos de cunho estratégico, que geralmente não devem ser disponibilizados em outros tipos de ambiente como, por exemplo, a $W e b$, mais propício aos ataques de hackers.

A terceira fase compreende a preservação e a conservação das informações/documentos. Pressupõe, ainda, que o restante do processo tenha sido realizado com qualidade e o máximo de eficiência.

A preservação é importante, principalmente porque as informações perdem seu valor muito rapidamente. Algumas questões em relação à preservação são essenciais como, por exemplo: quanto tempo preservar a informação?; é necessário o estabelecimento de uma política de preservação ou a conservação é automática?; é necessário o estabelecimento de uma política de descarte ou a eliminação é diretamente proporcional ao uso?. Avaliar todos esses aspectos é extremamente importante, porque, como já mencionado anteriormente, as informações relevantes podem se perder, bem como aquelas que não são utilizadas, mas por possuírem caráter estratégico, podem vir a ser úteis no futuro.

A preservação documental se apoia em conceitos bem definidos existentes na literatura. A avaliação deve ser realizada anteriormente à conservação, respeitando-se, por exemplo, a tabela de temporalidade e, assim, indicar quais são as informações/documentos que devem ser preservados ou eliminados.

Essa etapa tem por objetivo, também, colaborar com a constituição da memória institucional, resguardando, assim, os fatos e acontecimentos que foram destaque no desenvolvimento e no desempenho da organização.

O modelo proposto (FIG. 2) tem como objetivo principal colaborar com o processo decisório organizacional e definir os gestores responsáveis por essa tarefa tão importante para qualquer tipo de organização. Nesse sentido, o reconhecimento da importância da informação orgânica é vital para a aplicação do modelo, que tem como insumo básico o uso deste recurso. 


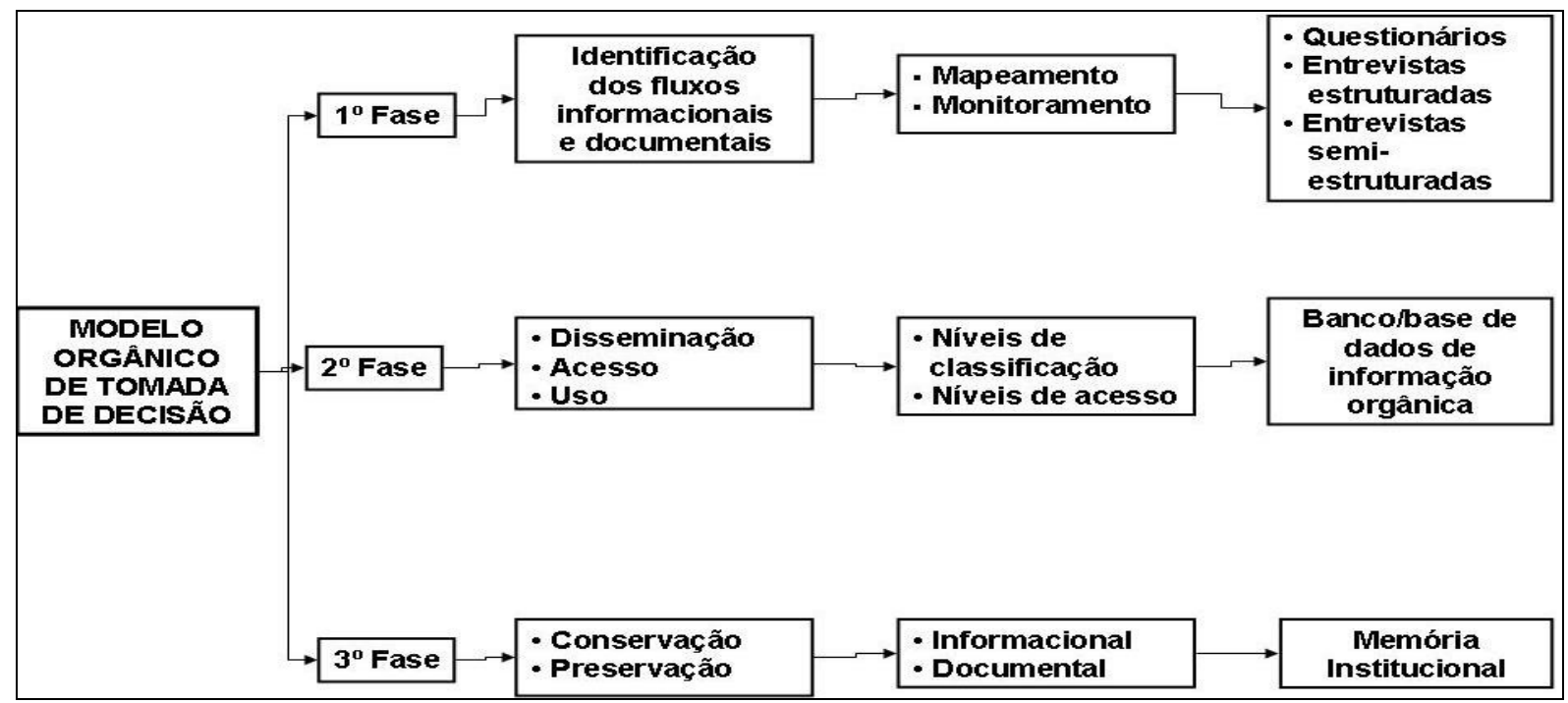

FIGURA 2 - Modelo orgânico de tomada de decisão

Fonte: Elaborado pelas autoras.

Neste modelo de tomada de decisão, a informação orgânica é o elemento chave. $O$ modelo possui três fases: a primeira tem por finalidade identificar os fluxos informacionais e documentais da organização, identificando os geradores/produtores de informação orgânica. Essa fase deve ser realizada periodicamente, de forma que sua dinâmica seja sempre atualizada, uma vez que a dinâmica organizacional e, por consequência, seus processos e fluxos se alteram. A segunda fase visa à disseminação, 0 acesso e 0 uso das informações orgânicas, sistematizando-as, de forma que no momento da tomada de decisão o gestor possa acessá-las e usá-las com segurança, eficiência e eficácia. A terceira e última fase envolve a preservação e a conservação dessas informações, atividades que contribuirão para a formação da memória organizacional.

\section{Considerações finais}

A partir da análise da literatura sobre essa temática foi possível compreender os modelos de tomada de decisão mais usuais em organizações.

Constatamos que a informação orgânica se constitui em um dos elementos responsáveis pela sobrevivência das organizações, visto que desempenha papel extremamente importante para o processo decisório. A informação orgânica é insumo e, ao mesmo tempo, produto dos processos organizacionais, o que a torna um recurso estratégico para o processo decisório.

Para este trabalho, consideramos quatro modelos de tomada de decisão: racional, processual, anárquico e político. Os modelos racional e processual apresentam características comuns. A diferença entre eles reside no fato de que o processual permite ajustes na decisão quando não se atinge os objetivos desejados. O modelo anárquico pode ser avaliado 
como o mais ambíguo entre eles, pois não apresenta regras e procedimentos pré-estabelecidos. O modelo político é diretamente influenciado pelos interesses dos atores do processo, a decisão geralmente não é a mais indicada para a solução do problema, mas, sim, a que irá satisfazer aos interesses dos envolvidos.

Observamos que todos os modelos apresentam algum tipo de similaridade, visto que todos utilizam a informação como recurso subsidiador da decisão. Nenhum dos modelos analisados apresenta como insumo principal a informação orgânica.

Compreendemos que a tomada de decisão é inerente ao trabalho de qualquer pessoa. No caso dos gestores, a tomada de decisão faz parte de sua função, ou seja, é tão importante quanto qualquer outra atividade sob sua responsabilidade. Nessa perspectiva, a informação orgânica é fundamental para o processo decisório de qualquer organização, porquanto vem colaborar com o desenvolvimento e aperfeiçoamento do trabalho dos gestores.

Ressaltamos a influência que a informação orgânica exerce em relação ao processo decisório, pois se apresenta como um recurso de caráter estratégico, colaborando para que os objetivos organizacionais possam ser atingidos, garantindo, assim, melhores resultados para a organização.

\section{Referências}

ALLISON, G. T. Essence of decision: explaining the Cuban missile crisis. Boston: Harper Collins, 1971. 338p.

BEUREN, I. M. Gerenciamento da informação: um recurso estratégico no processo de gestão empresarial. São Paulo: Atlas, 2000. 104p.

CHOO, C. W. A organização do conhecimento: como as organizações usam a informação para criar significado, construir conhecimento e tomar decisões. São Paulo: SENAC, 2003. 425p.

COHEN, M. D.; MARCH, J. G.; OLSEN. A garbage can model of organizational choice. Administrative Science Quarterly, Ithaca (NY), v. 17 , n. 1, p. 1-25, 1972.

CYERT, R. M.; MARCH, J. G. Behavioral theory of the firm. 2.ed. Oxford: Blackwell, 1992.

LOPES, L. C. A informação e os arquivos: teorias e práticas. Niterói: EDUFF; São Carlos: EDUFSCar, 1996. 142p.

LOUSADA, M.; VALENTIM, M. L. P. Informação orgânica como insumo do processo decisório empresarial. In: VALENTIM, M. L. P. (Org.) Gestão da informação e do conhecimento no âmbito da Ciência da Informação. São Paulo: Polis: Cultura Acadêmica, 2008. 268p. 
MARCH, J. G. A primer on decision making: how decisions happen. New York: Free Press, 1994. 290p.

MARCH, J. G.; SIMON, H. A. Limites cognitivos da racionalidade. In: . Teoria das organizações. Rio de Janeiro: FGV, 1975. p.192-220.

MELTSNER, A. J. Policy analysts in the bureaucracy. Berkeley: University of California Press, 1976. p. 77-79. apud CHOO, C. W. A organização do conhecimento: como as organizações usam a informação para criar significado, construir conhecimento e tomar decisões. São Paulo: SENAC, 2003. 425p.

MINTZBERG, H.; RAISINGHANI, D.; THÉORÊT, A. The structure of "unstructured" decision processes. Administrative Science Quarterly, Ithaca (NY), v. 21, n. 2, p. 246-274, 1976.

NIOCHE, J. P. et al. Strategor. strategie, structure, décision, identité: politique générale d'enterpisa. Paris: Inter Editions, 1993.

ROBBINS, S. P. Comportamento organizacional. 11.ed. São Paulo: Pearson Prentice Hall, 2005. 536p.

ROSSEAU, J. I.; COUTURE, C. O lugar da arquivística na gestão da informação. In: __ Os fundamentos da disciplina arquivística. Lisboa: Dom Quixote, 1998. p.61-76.

SIMON, H. A. Comportamento administrativo: estudo dos processos decisórios nas organizações administrativas. 2.ed. Rio de Janeiro: FGV Editora, 1971. 277p.

STONER, L. A. F.; FREEMAN, R. E. Administração. 5.ed. Rio de Janeiro: Prentice Hall do Brasil, 1992. 533p.

TEODÓSIO, A. S.; SILVA, E. E.; RODRIGUES, F. R. G. Discutindo o processo decisório: a contribuição dos principais modelos de análise. Disponível em: $<$ http://www.mettodo.com.br/pdf/Discutindo\%20o\%20Processo\%20Decisorio.pdf $>$. Acesso em: 11 dez. 2009. 